\title{
Comparative Study on Nobiletin Metabolism with Liver Microsomes from Rats, Guinea Pigs and Hamsters and Rat Cytochrome P450
}

\author{
Nobuyuki Koga, ${ }^{*, a}$ Miki Matsuo, ${ }^{a}$ Chiho Ohta,${ }^{a}$ Koichi Haraguchi,${ }^{b}$ Mikiko Matsuoka, ${ }^{a}$ \\ Yoshihisa KATO, ${ }^{d}$ Toshinao IshII, ${ }^{a}$ Masamichi YANO, ${ }^{c}$ and Hideaki OHTA ${ }^{a}$ \\ ${ }^{a}$ Faculty of Nutritional Sciences, Nakamura Gakuen University; 5-7-1 Befu, Johnan-ku, Fukuoka 814-0198, Japan: \\ ${ }^{b}$ Daiichi College of Pharmaceutical Sciences; 22-1 Tamagawa-cho, Minami-ku, Fukuoka 815-8511, Japan: ${ }^{c}$ Laboratory \\ of Postharvest Physiology, Department of Citriculture, National Institute of Fruit Tree Science; 485-6 Okitsu-cho, Shimizu, \\ Shizuoka 424-0292, Japan: and ${ }^{d}$ Kagawa School of Pharmaceutical Sciences, Tokushima Bunri University; 1314-1 Shido, \\ Sanuki, Kagawa 769-2193, Japan.
}

Received June 12, 2007; accepted September 18, 2007; published online September 19, 2007

\begin{abstract}
In vitro metabolism of nobiletin, a polymethoxy-flavonoid abundantly present in citrus peels, was studied using liver microsomes of rats, hamsters and guinea pigs and ten cDNA-expressed rat cytochrome P450 (P450). The effects of $\mathbf{P 4 5 0}$ inducers on nobiletin metabolism were also investigated. Aerobical incubation with NADPH and animal liver microsomes transformed nobiletin to five metabolites, M-1, M-2, M-3, M-4 and M-5. From LCMS and ${ }^{1} \mathrm{H}-\mathrm{NMR}$ data and a time-course study, these were assumed to be $4^{\prime}$-hydroxy (OH)-, 7-OH-, 6-OH-, $3^{\prime}, 4^{\prime}-$ diOH- and 6,7-diOH-metabolites, respectively. Pretreatment of animals with phenobarbital increased M-2 and M-3 to about 2-fold that in untreated animals. Pretreatment with 3-methylcholanthrene (MC) resulted in remarkable increases of both M-1 and M-4 (3 to 9-fold that of untreated). Males had 2-3 times higher M-2 and M-3 formation activities in rats, and for M-2 in hamsters than did females. Immunoinhibition study using antiserum against $\mathrm{P450}$ revealed the involvement of hamster CYP1A2 in the formation of M-1 and M-4 in hamster liver. Of ten rat P450s, CYP2C11, CYP3A1, CYP3A2 and CYP2D1 had high activities for the formation of M-1, M-2 and M-3. Another P450s (CYP1A1, CYP2C12 and CYP1A2) also showed activity for the formation of M-1. Only CYP1A1 produced 3',4'-diOH-metabolites (M-4). However, CYP2A1, CYP2B1 and CYP2E1 had no activity for nobiletin. These results suggested that constitutive P450s such as CYP2C11, CYP2D1, CYP3A1, CYP3A2 and CYP2C12 are responsible for the demethylation at the 6-, 7-, $3^{\prime}$ - and $4^{\prime}$-positions; whereas, MC-inducible P450s, CYP1A1 and CYP1A2, preferentially catalyzed demethylation at the $3^{\prime}$-and $4^{\prime}$-positions.
\end{abstract}

Key words nobiletin; metabolism; cytochrome P450; rat; guinea pig; hamster

Polymethoxy-flavonoids are naturally occurring compounds found abundantly in the juice and peel of citrus fruits such as Citrus nobilis, Citrus aurantium, Citrus hassaku and Citrus depressa Hayata (Rutaceae). They include nobiletin (5,6,7,8,3', $4^{\prime}$-hexamethoxyflavone), tangeretin $\left(5,6,7,8,4^{\prime}\right.$ pentamethoxyflavone), sinensetin $\left(5,6,7,3^{\prime}, 4^{\prime}\right.$-pentamethoxyflavone) and natsudaidain (3-hydroxy-5,6,7,8,3',4'-hexamethoxyflavone). ${ }^{1-5)}$ Studies have demonstrated that nobiletin possesses various biological properties such as anti-proliferative, ${ }^{6,7)}$ anti-carcinogenic, ${ }^{8-10)}$ and anti-inflammatoric ${ }^{11-13)}$ along with potent cell differencing activity. ${ }^{14-16)}$ For example, nobiletin suppresses inflammation through the inhibition of cyclooxygenase (COX)-2, a causal enzyme for skin inflammation and decreases tumor invasion through the suppression of matrix metalloproteinase 9 , a collagenase that hydrolyzes components of the cell matrix such as collagen and gelatin. It has also been reported that nobiletin inhibits the growth of tumor cells more potently than other polyhydroxyflavonoids including quercetin and taxifolin. ${ }^{7)}$ It is thought that nobiletin can enter into cells more easily than polyhydroxy-flavonoids due to its high lipophilicity.

Cytochrome P450 (P450) is a key enzyme catalyzing the oxidative metabolism of a large number of exogenous and endogenous compounds ${ }^{17)}$ and is reported to be involved in the metabolism of flavonoids. ${ }^{18)}$ Nielsen et al ${ }^{18,19)}$ used liver microsomes of Aroclor 1254 (a commercial PCB preparation)-pretreated rats to show that the main metabolic pathway of polyhydroxy-flavonoids such as apigenin, naringenin and kaempferol is a hydroxylation in the ring A or B of flavone molecule. They also showed that the main pathways of tangeretin are demethylation in ring A or B and hydroxylation at $3^{\prime}$-position of ring B. ${ }^{18,19)}$ Recent studies using recombinant human P450s have demonstrated that genistein, an isoflavone abundant in soy beans, is metabolized predominantly to $3^{\prime}$ OH-genistein by CYP1A1, CYP1A2, CYP1B1 and CYP2E1 and to two other metabolites by CYP3A4. ${ }^{20)}$ As well, the tangeretin metabolism has been shown to be catalyzed by CYP1A2, CYP3A4, CYP2D6 and CYP2C9. ${ }^{21)}$

On the other hand, there are not many reports on the biotransformation of nobiletin in animals. ${ }^{22-25)}$ Yasuda et al. found a few demethylated metabolites in $24 \mathrm{~h}$-urine of rats orally administered nobiletin and determined that a major metabolite is $4^{\prime}$-demethylated $\left(4^{\prime}-\mathrm{OH}\right)$ nobiletin. ${ }^{24)}$ However, the mechanism which the biological activities mentioned above are exerted by a parent compound or its metabolites remains obscure. For a better understanding of this point, it is very important to compare the metabolic profile of nobiletin in various animals and to elucidate which P450s are involved in the metabolism of nobiletin. Therefore, we investigated the in vitro metabolism of nobiletin using liver microsomes of rats, hamsters and guinea pigs, and ten recombinant rat P450s. We also examined the inductive effects of prototype P450 inducers, phenobarbital (PB) and 3-methylcholanthrene (MC), on nobiletin metabolism.

\section{MATERIALS AND METHODS}

Chemicals Nobiletin was purified from King juice (Cit- 
rus nobilis) as described previously. ${ }^{1)} \mathrm{PB}$ (Na salt) and $\mathrm{MC}$ were purchased from Wako Pure Chemical Industries, Ltd. (Osaka, Japan). Glucose-6-phosphate (G-6-P) and nicotinamide adenine dinucleotide phosphate $\left(\mathrm{NADP}^{+}\right)$were purchased from Oriental Yeast Co., Ltd. (Tokyo, Japan). G-6-P dehydrogenase from Bakers' yeast was purchased from Sigma-Aldrich Co. (St. Louis, MO, U.S.A). All other chemicals used were of the highest purity commercially available.

Animals and Treatment Nine males and three females each of Wistar rats (body weight about $200 \mathrm{~g}$, 5 weeks old), Hartley guinea pigs (body weight about $250 \mathrm{~g}, 4$ weeks old) and Golden Syrian hamsters (body weight about $90 \mathrm{~g}, 7$ weeks old) were used. The male animals were divided to untreated, PB-treated and MC-treated groups ( $n=3$ each). PB and $\mathrm{MC}$ were dissolved in saline and corn oil and injected intraperitoneally (i.p.) at doses of $80 \mathrm{mg} / \mathrm{kg} / \mathrm{d}$ for $3 \mathrm{~d}$ and 20 $\mathrm{mg} / \mathrm{kg} / \mathrm{d}$ for $3 \mathrm{~d}$, respectively. Animals were killed $24 \mathrm{~h}$ after the last injection of each inducer. Preparation of animal liver microsomes was done as reported. ${ }^{26)}$ All procedures were conducted in accordance with "The Guide for the Care and Use of Laboratory Animals" of Nakamura Gakuen University.

Recombinant P450s Supersomes from baculovirus insect cells containing recombinant reductase and rat $\mathrm{P} 450 \mathrm{~s}$, CYP1A1, CYP1A2, CYP2A1, CYP2B1, CYP2C11, CYP2C12, CYP2D1, CYP2E1, CYP3A1 and CYP3A2, were purchased from Gentest Corp. (Woburn, MA, U.S.A).

Microsomal Metabolism of Nobiletin $0.28 \mathrm{~mm}$ Nobiletin dissolved in $5 \mu \mathrm{l}$ of dimethylsulfoxide, $6 \mathrm{~mm} \mathrm{MgCl}_{2}$, $100 \mathrm{~mm}$ HEPES buffer ( $\mathrm{pH}$ 7.4), NADPH-generating system (0.33 mm NADP ${ }^{+}, 5$ mm G-6-P, 1 unit of G-6-P dehydrogenase) and $2 \mathrm{mg}$ of microsomal protein in a final volume of $1 \mathrm{ml}$ was used. Incubation was initiated by adding the NADPH-generating system and was run at $37^{\circ} \mathrm{C}$ for $20 \mathrm{~min}$. After incubation, $3 \mathrm{ml}$ of the ice-cold methanol was added to the incubation mixture to stop the reaction. Then the mixture was kept on ice for more than $30 \mathrm{~min}$ to denature the microsomal protein. After centrifugation at $1600 \times \boldsymbol{g}$ for $10 \mathrm{~min}$, an aliquot of the supernatant was isolated and injected to HPLC system. The HPLC conditions were: column, Hibar RT 250-4 $(250 \times 4.5 \mathrm{~mm}$ i.d., $5 \mu \mathrm{m})$ attached directly with a guard column (LiChrospher $100 \mathrm{RP}-18$; $0.5 \times 4 \mathrm{~mm}$ i.d., $5 \mu \mathrm{m}$ ); mobile phase, methanol-0.01 $\mathrm{M}$ phosphoric acid $(3: 7, \mathrm{v} / \mathrm{v})$; flow rate, $1.0 \mathrm{ml} / \mathrm{min}$; detection wavelength, $340 \mathrm{~nm}$. Assuming that each metabolite shows the same intensity of absorbance at $340 \mathrm{~nm}$ as nobiletin, the formation rates of metabolites were calculated using the calibration curve of nobiletin. To isolate and purify each metabolite, a $100 \mathrm{ml}$-incubation was performed using liver microsomes of PB- and MC-treated guinea pigs. After incubation, the incubation mixture was extracted three times with $300 \mathrm{ml}$ of ethyl acetate. The pooled organic phase was evaporated to dryness, dissolved with methanol and applied to preparative HPLC. The HPLC conditions used were: column, YMC-ODS $(250 \times 20 \mathrm{~mm}$ i.d., $5 \mu \mathrm{m}$ ) connected with a guard column (YMC-Guardpack ODS; $50 \times 20 \mathrm{~mm}$ i.d., $5 \mu \mathrm{m})$; mobile phase, methanol- 0.01 $\mathrm{M}$ phosphoric acid $(3: 7, \mathrm{v} / \mathrm{v})$; flow rate, $4.0 \mathrm{ml} / \mathrm{min}$; detection wavelength, $340 \mathrm{~nm}$.

Nobiletin Metabolism by Recombinant Rat P450 A $0.5 \mathrm{ml}$ of incubation mixture containing rat P450 (20-85 pmol), 0.33 mм NADP ${ }^{+}, 5$ mм G-6-P, 0.5 unit G-6-P dehy- drogenase, $6 \mathrm{~mm} \mathrm{MgCl}_{2}$ and $0.28 \mathrm{~mm}$ nobiletin in $100 \mathrm{~mm}$ Tris- $\mathrm{HCl}\left(\mathrm{pH} \mathrm{7.4)}\right.$ was incubated at $37^{\circ} \mathrm{C}$ for $30 \mathrm{~min}$ in a $1.5-$ $\mathrm{ml}$ plastic tube. The incubation was started by the addition of the NADPH-generating system (NADP, G-6-P and G-6-P dehydrogenase) and stopped by the addition of $1.5 \mathrm{ml}$ of ice colded-methanol. After centrifugation at $1600 \times \boldsymbol{g}$ for $10 \mathrm{~min}$, the supernatant was isolated and an aliquot of the supernatant injected to the HPLC system. The HPLC conditions were the same as described above.

Inhibition of Nobiletin Metabolism with Antisera against Hamster CYP1A2 Antiserum against hamster CYP1A2 was prepared as reported previously. ${ }^{27,28)}$ Liver microsomes from hamsters were preincubated with antiserum against hamster $\mathrm{CYP} 1 \mathrm{~A} 2$ at $30^{\circ} \mathrm{C}$ for $30 \mathrm{~min}$, respectively. The incubation was initiated by adding nobiletin and $\mathrm{NADPH}$-generating system and was run for $30 \mathrm{~min}$ at $37^{\circ} \mathrm{C}$. Analysis of metabolites was made by HPLC as described above.

Analytical Methods The ${ }^{1} \mathrm{H}-\mathrm{NMR}$ spectra of nobiletin and its metabolites were obtained on a JEOL GSX-500 spectrometer $(500 \mathrm{MHz})$. Samples were dissolved in chloroform$d$ with tetramethylsilane as an internal standard. LC-MS was done using a JASCO Liquid Chromatograph Gulliver Series LCSS-905 equipped with a mass selective detector under the following conditions: column, a Wakosil ODS $(150 \times 2 \mathrm{~mm}$ i.d., $5 \mu \mathrm{m})$; mobile phase, methanol- $0.1 \%$ acetic acid $(3: 2$, $\mathrm{v} / \mathrm{v}$ ) and; flow rate, $0.2 \mathrm{ml} / \mathrm{min}$.

Other Methods Protein measurements were made by the method of Lowry et al. ${ }^{29)}$ using bovine serum albumin as a standard.

\section{RESULTS}

Species Differences in the Microsomal Metabolism of Nobiletin and Effects of $\mathbf{P 4 5 0}$ Inducers Figure 1 shows HPLC chromatograms of nobiletin and its metabolites formed by liver microsomes from untreated, PB-treated and MC-treated rats. In untreated rats, three metabolites, M-1, M2 and M-3, were found at retention times of 6.1, 5.3 and 4.8 min, respectively. Pretreatment of $\mathrm{PB}$ and MC resulted in the formation of two more metabolites, M-4 and M-5, with retention times of 4.1 and $3.7 \mathrm{~min}$, respectively.

In Table 1, we compare the formation rates of nobiletin metabolites by liver microsomes of rats, hamsters and guinea pigs. Untreated rat liver microsomes formed M-2, M-1 and M-3 at a rate of $0.59,0.37$ and $0.24 \mathrm{nmol} / \mathrm{min} / \mathrm{mg}$ protein, respectively. Similarly, untreated hamsters formed M-2 to a greater extent compared to the other four metabolites with activity that was three times higher than that in rats. Although M-4 and M-5 were also formed in untreated hamsters, both had values less than $30 \%$ of that of M-2. By contrast, untreated guinea pigs produced the five metabolites with much higher activity than did rats and hamsters. Of all metabolites, M-1 was the most abundant. The amounts of M1 and M-2 were 4.6-fold and 1.6-fold, respectively, of those values in rats. The amounts of M-4 and M-5 were also 9.7fold and 7.2-fold, respectively, of those values in hamsters.

Table 1 shows the effects of P450 inducers on nobiletin metabolism. PB-treatment increased the formation of M-2 and M-3 to about 2.2-fold of that in untreated rats and to about 2.5 -fold of that in untreated guinea pigs. In hamsters, 
PB-treatment increased only M-3 to 1.9-fold of untreated ones. MC-treatment resulted in a remarkable increase (6- to 8-fold of untreated) of M-1 and M-4 in rats and hamsters and an about 2-fold increase of both metabolites in guinea pigs. By contrast, the formation of M-2 and M-3 decreased in all species treated with $\mathrm{MC}$. These results suggested that PB-inducible P450s such as CYP2B subfamily enzymes mainly catalyze the formation of $\mathrm{M}-2$ and $\mathrm{M}-3$, whereas MC-inducible P450s such as CYP1A subfamily enzymes are im-

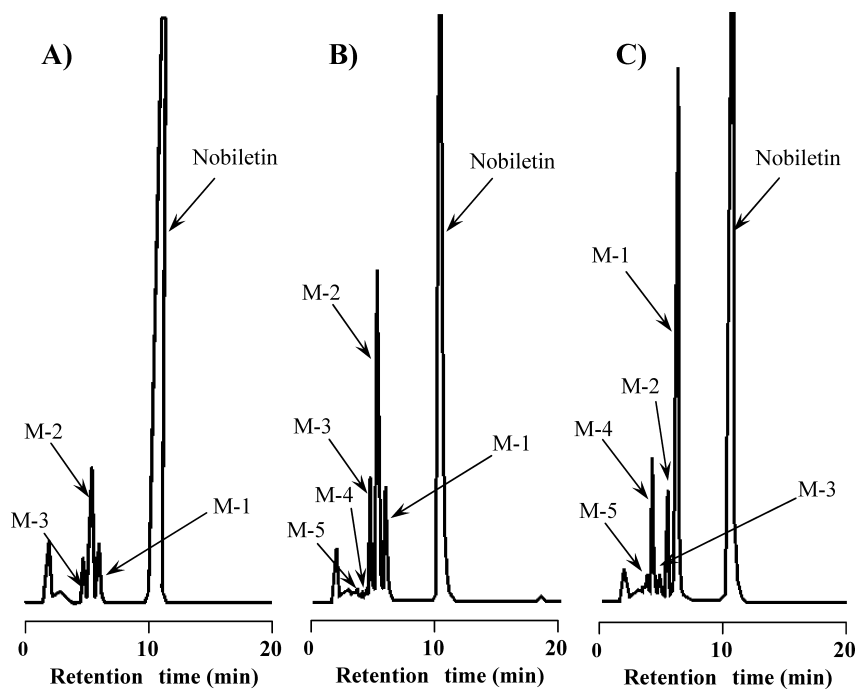

Fig. 1. HPLC Chromatograms of Nobiletin Metabolites Formed by Liver Microsomes of Untreated (A), PB-Treated (B) and MC-Treated (C) Rats portant in the formation of M-1 and M-4.

Sex Differences in the Microsomal Metabolism of Nobiletin As shown in Table 1, sex differences in the nobiletin metabolism were observed in rats and hamsters. In female rats, the formation activity of M-2 and M-3 was significantly lower being $29 \%$ and $45 \%$, respectively, of male rats. These results suggested that a male-specific P450, CYP2C11, would be responsible for the formation of both metabolites rather than a female-specific P450, CYP2C12. Additionally, female hamsters formed $\mathrm{M}-2$ at a slower rate than did male ones. On the other hand, there was no sex difference in guinea pigs.

Time-Course Study in Nobiletin Metabolism in Rats For data regarding the metabolic pathways of nobiletin, we analyzed five metabolites formed during the incubation times indicated (Fig. 2). The amounts of M-1, M-2 and M-3 increased linearly up to $10 \mathrm{~min}$ of incubation time. However, there was a lag in the appearance of M-4 and M-5. These results suggested that M-4 and M-5 were secondary oxidative metabolites. Along with the fact that M-1 and M-4 were increased by MC-microsomes, M-4 is suggested to be a secondary metabolite formed from M-1.

Chemical Structures of Metabolites To determine the chemical structures of the five metabolites, a large scale-incubation $(100 \mathrm{ml})$ was performed using PB- and MC-treated guinea pig microsomes. The five metabolites were extracted with ethyl acetate and applied to LC-MS. In Table 2, mass spectral data shows that three metabolites, M-1, M-2 and M3 , were determined as having the same molecular weight of 388 while both M-4 and M-5 had a molecular weight of 374 ;

Table 1. Effects of P450 Inducers on Nobiletin Metabolism in Rats, Hamsters and Guinea Pigs

\begin{tabular}{|c|c|c|c|c|c|c|}
\hline \multirow{2}{*}{ Treatment } & \multirow{2}{*}{ Sex } & \multicolumn{5}{|c|}{ Metabolite formed (nmol/min/mg protein) } \\
\hline & & M-1 & M-2 & M-3 & M-4 & M-5 \\
\hline \multicolumn{7}{|l|}{ Rat } \\
\hline None & 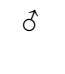 & $\begin{array}{c}0.371 \pm 0.057 \\
(100)\end{array}$ & $\begin{array}{c}0.586 \pm 0.035 \\
(100)\end{array}$ & $\begin{array}{c}0.237 \pm 0.022 \\
(100)\end{array}$ & N.D. & N.D. \\
\hline $\mathrm{PB}$ & $\hat{\sigma}$ & $\begin{array}{c}0.598 \pm 0.021 * \\
(161)\end{array}$ & $\begin{array}{c}1.265 \pm 0.131 * \\
(216)\end{array}$ & $\begin{array}{c}0.517 \pm 0.054 * \\
(218)\end{array}$ & $0.020 \pm 0.034$ & $0.089 \pm 0.010^{*}$ \\
\hline $\mathrm{MC}$ & $\hat{o}$ & $\begin{array}{c}3.218 \pm 0.039 * \\
(867)\end{array}$ & $\begin{array}{c}0.518 \pm 0.041 \\
(88)\end{array}$ & $\begin{array}{c}0.163 \pm 0.026^{*} \\
(69)\end{array}$ & $0.765 \pm 0.027 *$ & $0.137 \pm 0.011^{*}$ \\
\hline None & q & $\begin{array}{c}0.420 \pm 0.046 \\
(113)\end{array}$ & $\begin{array}{c}0.172 \pm 0.035 * \\
(29)\end{array}$ & $\begin{array}{c}0.107 \pm 0.024 * \\
(45)\end{array}$ & N.D. & N.D. \\
\hline \multicolumn{7}{|l|}{ Hamster } \\
\hline None & 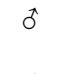 & $\begin{array}{c}0.170 \pm 0.023 \\
(100)\end{array}$ & $\begin{array}{c}1.533 \pm 0.071 \\
(100)\end{array}$ & $\begin{array}{c}0.240 \pm 0.021 \\
(100)\end{array}$ & $\begin{array}{c}0.041 \pm 0.007 \\
(100)\end{array}$ & $\begin{array}{c}0.041 \pm 0.013 \\
(100)\end{array}$ \\
\hline PB & $\hat{0}$ & $\begin{array}{c}0.171 \pm 0.001 \\
(101)\end{array}$ & $\begin{array}{c}1.518 \pm 0.080 \\
(99)\end{array}$ & $\begin{array}{c}0.450 \pm 0.013 * \\
(188)\end{array}$ & $\begin{array}{c}0.031 \pm 0.002 \\
(76)\end{array}$ & $\begin{array}{c}0.024 \pm 0.021 \\
(59)\end{array}$ \\
\hline $\mathrm{MC}$ & $\hat{\sigma}$ & $\begin{array}{c}1.103 \pm 0.021 * \\
(649)\end{array}$ & $\begin{array}{c}1.094 \pm 0.012 * \\
(71)\end{array}$ & $\begin{array}{c}0.107 \pm 0.011 * \\
(45)\end{array}$ & $\begin{array}{c}0.330 \pm 0.010^{*} \\
(801)\end{array}$ & N.D. \\
\hline None & q & $\begin{array}{c}0.159 \pm 0.021 \\
(94)\end{array}$ & $\begin{array}{c}0.836 \pm 0.022 * \\
(55)\end{array}$ & $\begin{array}{c}0.275 \pm 0.017 \\
(115)\end{array}$ & $\begin{array}{c}0.059 \pm 0.018 \\
(144)\end{array}$ & $\begin{array}{c}0.038 \pm 0.007 \\
(93)\end{array}$ \\
\hline \multicolumn{7}{|l|}{ Guinea pig } \\
\hline None & $\hat{o}$ & $\begin{array}{c}1.716 \pm 0.304 \\
(100)\end{array}$ & $\begin{array}{c}0.930 \pm 0.118 \\
(100)\end{array}$ & $\begin{array}{c}0.240 \pm 0.019 \\
(100)\end{array}$ & $\begin{array}{c}0.397 \pm 0.119 \\
(100)\end{array}$ & $\begin{array}{c}0.294 \pm 0.103 \\
(100)\end{array}$ \\
\hline PB & $\hat{\sigma}$ & $\begin{array}{l}0.923 \pm 0.135 \\
\quad(54)\end{array}$ & $\begin{array}{c}2.277 \pm 0.217^{*} \\
(245)\end{array}$ & $\begin{array}{c}0.633 \pm 0.065 * \\
(264)\end{array}$ & $\begin{array}{c}0.444 \pm 0.239 \\
(112)\end{array}$ & $\begin{array}{c}0.239 \pm 0.035 \\
(81)\end{array}$ \\
\hline $\mathrm{MC}$ & $\hat{\sigma}$ & $\begin{array}{c}3.577 \pm 0.426^{*} \\
\quad(208)\end{array}$ & $\begin{array}{c}0.431 \pm 0.017^{*} \\
(46)\end{array}$ & $\begin{array}{c}0.182 \pm 0.018 * \\
(76)\end{array}$ & $\begin{array}{c}1.143 \pm 0.170^{*} \\
(288)\end{array}$ & $\begin{array}{c}0.495 \pm 0.043 \\
(168)\end{array}$ \\
\hline None & q & $\begin{array}{c}1.730 \pm 0.275 \\
(101)\end{array}$ & $\begin{array}{c}0.996 \pm 0.011 \\
(107)\end{array}$ & $\begin{array}{c}0.248 \pm 0.018 \\
(103)\end{array}$ & $\begin{array}{c}0.428 \pm 0.024 \\
(108)\end{array}$ & $\begin{array}{c}0.414 \pm 0.197 \\
(141)\end{array}$ \\
\hline
\end{tabular}

N.D., not detected. $*$ Significantly different from untreated male animals $(p<0.05)$. Values are mean \pm S.D. of three animals and those in parentheses are the relative ratio of untreated male animals. 

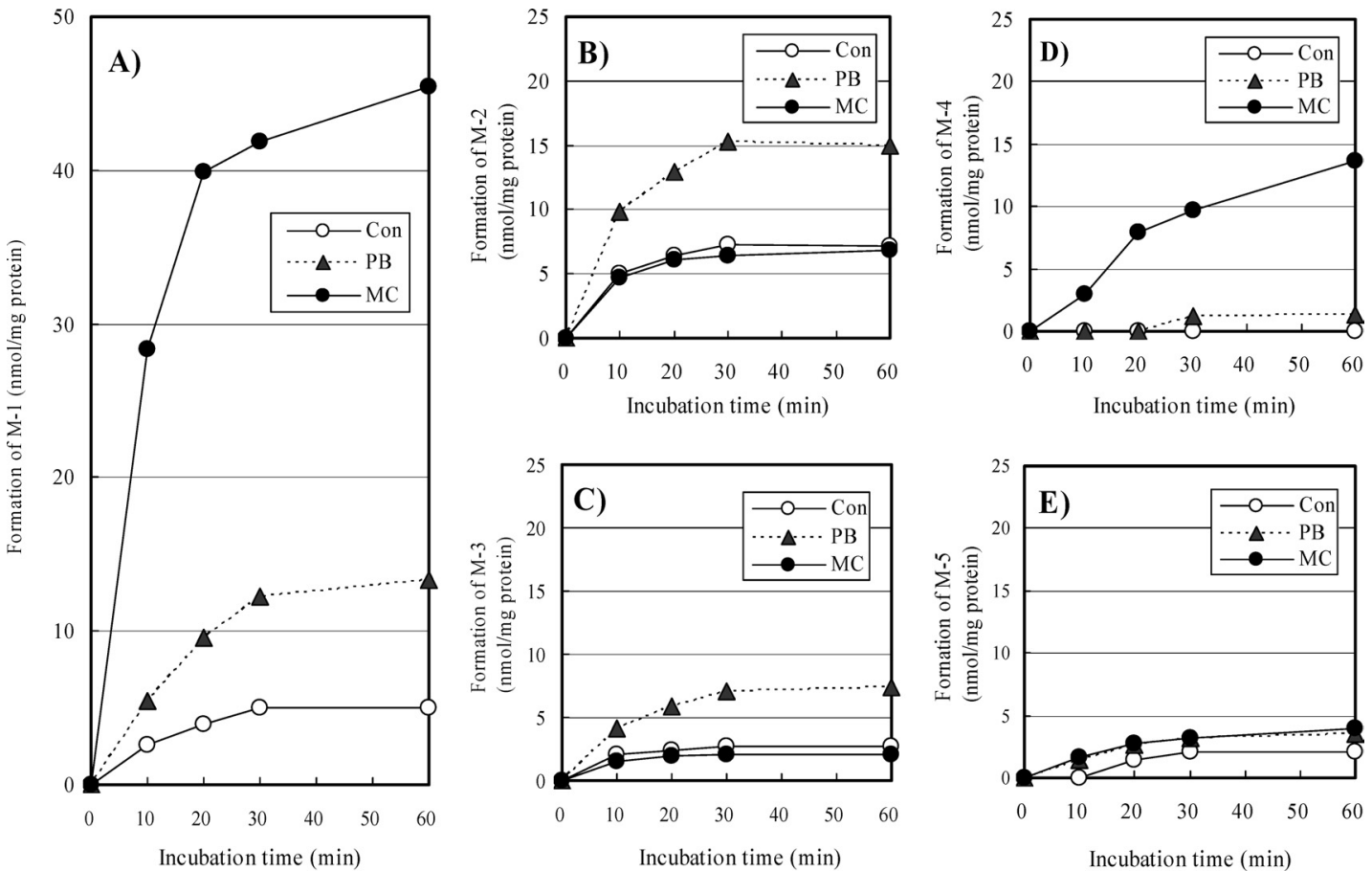

Fig. 2. Time Courses of Nobiletin Metabolism by Liver Microsomes of Untreated, PB- and MC-Treated Rats

Each figure shows the amount of metabolites, M-1 (A), M-2 (B), M-3 (C), M-4 (D) and M-5 (E) formed during the incubation time indicated. Each point represents the mean of duplicate determinations.

Table 2. Mass and ${ }^{1} \mathrm{H}-\mathrm{NMR}$ Spectral Data of Nobiletin and Its Metabolites

\begin{tabular}{|c|c|c|c|c|c|c|c|}
\hline & & Nobiletin & M-1 & M-2 & M-3 & $\mathrm{M}-4^{a)}$ & M-5 \\
\hline Molecula & weight & 402 & 388 & 388 & 388 & 374 & 374 \\
\hline \multicolumn{8}{|c|}{ Chemical shift (ppm) of protons in ${ }^{1} \mathrm{H}-\mathrm{NMR}$} \\
\hline \multirow[t]{4}{*}{ A-ring } & $\mathrm{C}-5$ & $4.02(3 \mathrm{H}, \mathrm{s})$ & $4.02(3 \mathrm{H}, \mathrm{s})$ & $4.04(3 \mathrm{H}, \mathrm{s})$ & $4.04(3 \mathrm{H}, \mathrm{s})$ & - & $4.04(3 \mathrm{H}, \mathrm{s})$ \\
\hline & C-6 & $3.95(3 \mathrm{H}, \mathrm{s})$ & $3.95(3 \mathrm{H}, \mathrm{s})$ & $3.97(3 \mathrm{H}, \mathrm{s})$ & $3.95(3 \mathrm{H}, \mathrm{s})$ & - & N.D. \\
\hline & $\mathrm{C}-7$ & $3.95(3 \mathrm{H}, \mathrm{s})$ & $3.95(3 \mathrm{H}, \mathrm{s})$ & 3.91 (3त, & $\int^{3.90(3 \pi,}$ & - & N.D. \\
\hline & $\mathrm{C}-8$ & $4.10(3 \mathrm{H}, \mathrm{s})$ & $4.10(3 \mathrm{H}, \mathrm{s})$ & $4.14(3 \mathrm{H}, \mathrm{s})$ & $4.07(3 \mathrm{H}, \mathrm{s})$ & - & $4.14(3 \mathrm{H}, \mathrm{s})$ \\
\hline \multirow[t]{5}{*}{ B-ring } & $\mathrm{C}-2^{\prime}$ & $7.41(1 \mathrm{H}, \mathrm{d}, J=1.8 \mathrm{~Hz})$ & $7.40(1 \mathrm{H}, \mathrm{d}, J=1.8 \mathrm{~Hz})$ & $7.42(1 \mathrm{H}, \mathrm{s})$ & $7.40(1 \mathrm{H}, \mathrm{s})$ & - & $7.40(1 \mathrm{H}, \mathrm{s})$ \\
\hline & $\mathrm{C}-3^{\prime}$ & $3.97(3 \mathrm{H}, \mathrm{s})$ & $400(3 \mathrm{H} s)$ & $3.98(3 \mathrm{H}, \mathrm{s})$ & $3.97(3 \mathrm{H}, \mathrm{s})$ & - & $4.00(3 \mathrm{H}, \mathrm{s})$ \\
\hline & $\mathrm{C}-4^{\prime}$ & $3.98(3 \mathrm{H}, \mathrm{s})$ & $\int^{4.00(3 \pi, \mathrm{s})}$ & $4.00(3 \mathrm{H}, \mathrm{s})$ & $3.98(3 \mathrm{H}, \mathrm{s})$ & - & $4.00(3 \mathrm{H}, \mathrm{s})$ \\
\hline & $\mathrm{C}-5^{\prime}$ & $6.99(1 \mathrm{H}, \mathrm{d}, J=8.8 \mathrm{~Hz})$ & $7.04(1 \mathrm{H}, \mathrm{d}, J=7.0 \mathrm{~Hz})$ & $7.00(1 \mathrm{H}, \mathrm{d}, J=8.1 \mathrm{~Hz})$ & $7.00(1 \mathrm{H}, \mathrm{d}, J=8.4 \mathrm{~Hz})$ & - & $7.05(1 \mathrm{H}, \mathrm{d}, J=8.1 \mathrm{~Hz})$ \\
\hline & C-6' & $7.57(1 \mathrm{H}, \mathrm{dd}, J=2.2,8.8 \mathrm{~Hz})$ & $7.53(1 \mathrm{H}, \mathrm{d}, J=8.4 \mathrm{~Hz})$ & $7.57(1 \mathrm{H}, \mathrm{d}, J=8.4 \mathrm{~Hz})$ & $7.57(1 \mathrm{H}, \mathrm{d}, J=6.6 \mathrm{~Hz})$ & - & $7.53(1 \mathrm{H}, \mathrm{d}, J=6.2 \mathrm{~Hz})$ \\
\hline C-ring & $\mathrm{C}-3$ & $6.62(1 \mathrm{H}, \mathrm{s})$ & $6.60(1 \mathrm{H}, \mathrm{s})$ & $6.63(1 \mathrm{H}, \mathrm{s})$ & $6.61(1 \mathrm{H}, \mathrm{s})$ & - & $6.61(1 \mathrm{H}, \mathrm{s})$ \\
\hline
\end{tabular}

—, not determined. N.D., not detected. $a$ ) The ${ }^{1}$ H-NMR spectrum was not assigned due to the low recovery of M-4.

indicating that they were monohydroxy $(\mathrm{OH})$ - and dihydroxy (diOH)-metabolites, respectively, which meant a loss of one and two methyl groups, respectively, from nobiletin.

Table 2 also presents the ${ }^{1} \mathrm{H}-\mathrm{NMR}$ data of nobiletin and its metabolites. By comparing their spectral data with those reported previously, ${ }^{2,3,30)}$ the six methoxy $(\mathrm{MeO})$ group of nobiletin were assigned to $4.02 \mathrm{ppm}$ (5-MeO), $3.95 \mathrm{ppm}$ (6$\mathrm{MeO}$ and 7-MeO) and $4.10 \mathrm{ppm}(8-\mathrm{MeO}), 3.97 \mathrm{ppm}\left(3^{\prime}-\right.$ $\mathrm{MeO})$ and $3.98 \mathrm{ppm}\left(4^{\prime}-\mathrm{MeO}\right)$. The protons at the 3-, $2^{\prime}-, 5^{\prime}-$ and $6^{\prime}$-positions were observed at 6.62, 7.41, 6.99 and 7.57 ppm, respectively. The ${ }^{1} \mathrm{H}-\mathrm{NMR}$ spectrum of $\mathrm{M}-1$ showed the presence of four $\mathrm{MeO}$ groups in ring $\mathrm{A}$ of the flavone molecule and the disappearance of the signals of the $3^{\prime}$ - or $4^{\prime}-\mathrm{MeO}$ group, indicating demethylation at the $3^{\prime}$ - or $4^{\prime}$-position in ring B. Next, when compared with the report of Herz and Kulanthaivel, ${ }^{30)}$ the ${ }^{1} \mathrm{H}-\mathrm{NMR}$ spectrum of M-1 was in complete agreement with that of $4^{\prime}$-demethylated nobiletin
(4'-OH-metabolite) reported in their paper. M-5 was assigned as 6,7-diOH-metabolite because of the disappearance of both signals of the 6- and 7-MeO groups. On the other hand, the ${ }^{1} \mathrm{H}-\mathrm{NMR}$ spectra of M-2 and M-3 showing four singlets derived from four $\mathrm{MeO}$ groups at the 5-, 8-, 3'- and 4' positions and one singlet derived from a $\mathrm{MeO}$ group at the 6or 7-position were quite similar with each other. However, the singlet of the $8-\mathrm{MeO}$ group of $\mathrm{M}-2$ was observed at a little lower field $(\delta 4.14 \mathrm{ppm})$ than that of M-3 $(\delta 4.07 \mathrm{ppm})$. These results agreed with those for M-5 (6,7-diOH-metabolite) in this study, and 7-OH-3,5,6,8, $3^{\prime}, 4^{\prime}$-hexamethoxyflavone as reported by Chen et $a l^{3)}$ This suggested that $\mathrm{M}-2$ and $\mathrm{M}-3$ are 7-OH- and 6-OH-nobiletin, respectively. We could not obtain the ${ }^{1} \mathrm{H}-\mathrm{NMR}$ spectrum of M-4 because of its low recovery.

Inhibitory Effects on Nobiletin Metabolism of Antiserum against Hamster CYP1A2 Although two hamster 
P450s, CYP1A1 and CYP1A2, are typical ones induced by MC-treatment, CYP1A1 is known to be expressed in the lung but not in the liver. ${ }^{31)}$ To clarify the contribution of CYP1A2 to nobiletin metabolism, antiserum against CYP1A2 was added to the incubation mixture including liver microsomes of MC-treated hamsters. As shown in Fig. 3, the addition of the antiserum $(200 \mu \mathrm{l})$ resulted in almost complete inhibition of the formation of M-1 and M-4 but not of M-2 and M-3 in MC-treated hamsters. These results confirmed that hamster CYP1A2 catalyzes the oxidative demethylation predominantly at the $3^{\prime}$ - and $4^{\prime}$-positions of ring $\mathrm{B}$.

Nobiletin Metabolism by Rat P450s Nobiletin metabolism by ten recombinant rat P450s (CYP1A1, CYP1A2, CYP2A1, CYP2B1, CYP2C11, CYP2C12, CYP2D1, CYP2E1, CYP3A1 and CYP3A2) was investigated. As shown in Fig. 4, among these enzymes, CYP2C11 (a malespecific $\mathrm{P} 450$ ) was the most active and showed the highest activity for the formation of M-1 and M-2 (23-30 $\mathrm{nmol} / \mathrm{min} / \mathrm{nmol} \mathrm{P} 450)$ and a relatively high activity for M-3 formation $(5 \mathrm{nmol} / \mathrm{min} / \mathrm{nmol} \mathrm{P} 450)$. CYP2C12 (a femalespecific $\mathrm{P} 450)$ produced only $\mathrm{M}-1$ at a much slower rate than CYP2C11. CYP3A1 and CYP3A2 showed similar metabolic pattern to form three OH-metabolites (M-2, M-3 and M-1) at rates of $13-14,3-5$ and $0.5-2 \mathrm{nmol} / \mathrm{min} / \mathrm{nmol} \mathrm{P} 450$, respectively. CYP2D1 also produced three $\mathrm{OH}$-metabolites
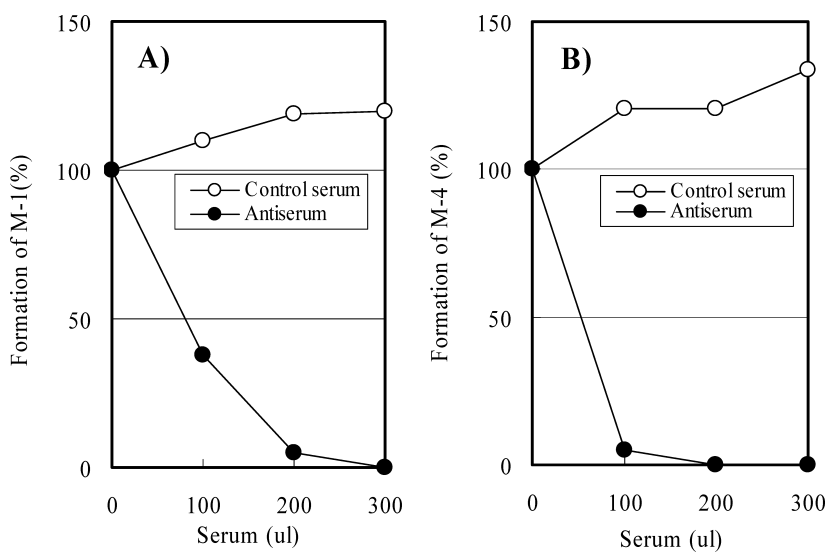

Fig. 3. Effect of Antiserum against Hamster CYP1A2 on the Formation of M-1 (A) and M-4 (B) with Liver Microsomes of MC-Treated Hamsters Each point represents the mean of duplicate determinations. with the order of $\mathrm{M}-3>\mathrm{M}-2>\mathrm{M}-1$. On the other hand, $\mathrm{MC}$ inducible CYP1A1 and CYP1A2 formed M-1 at rates of 18 and $3 \mathrm{nmol} / \mathrm{min} / \mathrm{nmol} \mathrm{P} 450$, respectively. Only CYP1A1 also formed M-4 (3',4'-diOH-metabolite), but none of ten P450s used here catalyzed the formation of M-5 (6,7-diOH-metabolite). CYP2A1, CYP2E1 and CYP2B1 (a PB-inducible P450) had no activity for nobiletin.

\section{DISCUSSION}

Several studies have reported that nobiletin possesses has various efficacies against cancer and can suppress inflammation and oxidative reactions. ${ }^{8-13)}$ To fully evaluate such biological activities, the biotransformation of nobiletin is essential. In this study we first demonstrated that nobiletin is metabolized to three $\mathrm{OH}$-metabolites and two diOH-metabolites by liver microsomes of rats, hamsters and guinea pigs. From LC-MS and ${ }^{1} \mathrm{H}-\mathrm{NMR}$ data and time-course studies, the structures of M-1, M-2, M-3, M-4 and M-5 were assumed to be 4'-OH-, 7-OH-, 6-OH-, 3',4'-diOH- and 6,7-diOH-metabolite, respectively. The metabolic pathways we postulated are shown in Fig. 5. Nobiletin metabolism only proceeded via oxidative demethylation at 6-, 7-, 3'- and 4'-positions in all animals used in this study. Similarly, tangeretin is metabolized via $3^{\prime}$-hydroxylation and demethylation at the 4'-, 6- or 7-positions in rat liver. ${ }^{18)}$ These results indicated that $\mathrm{P} 450$ enzymes selectively attack the 6-, 7-, 3'- or 4'-positions of polymethoxy-flavonoids.

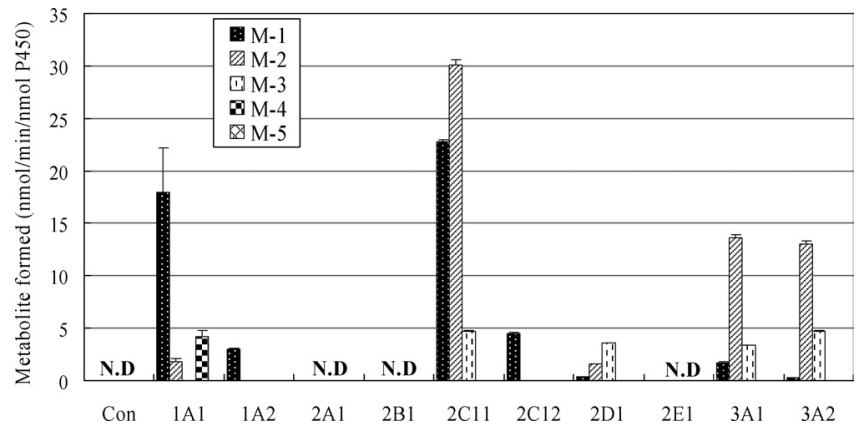

Fig. 4. Metabolism of Nobiletin by Ten Recombinant Rat Cytochrome P450s

Each bar represents the mean \pm S.D. of three determinations. Con represents supersomes from baculovirus insect cells containing only recombinant $\mathrm{P} 450$ reductase. N.D. not detected.

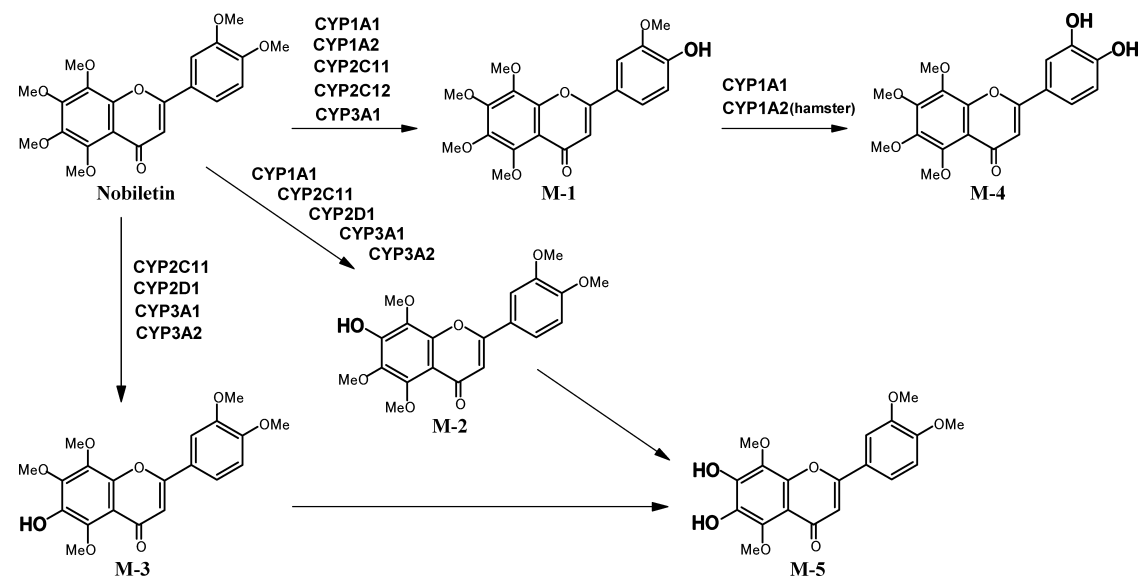

Fig. 5. Postulated Metabolic Pathways of Nobiletin in Animal Liver 
Some recombinant human $\mathrm{P} 450 \mathrm{~s}$ such as CYP1A2, CYP2C9, CYP2D6 and CYP3A4 have been reported to be responsible for the metabolism of tangeretin to form to $4^{\prime}$ $\mathrm{OH}-, 3^{\prime}, 4^{\prime}$-diOH-, 7,4'-diOH- and 6,7-diOH-tangeretin, respectively. $^{20,21)}$ In this study, seven recombinant rat $\mathrm{P} 450 \mathrm{~s}$ (CYP2C11， CYP1A1， CYP3A1， CYP3A2， CYP2D1, CYP2C12 and CYP1A2) were active in nobiletin metabolism, but a major PB-inducible CYP2B1, CYP2A1 and CYP2E1 had no activity. Furthermore, we observed sex differences in liver microsomal metabolism of nobiletin in both rats and hamsters, but not in guinea pigs (Table 1). Such a sex difference in rats could be explained by the catalytic activities of CYP2C11 and CYP2C12 for nobiletin. Considering these results, it was suggested that the P450 enzymes of the CYP1A, CYP2C, CYP2D and CYP3A subfamilies are the most important in the metabolism of polymethoxyflavonoids in mammals.

The guinea pig appears to be the most useful animal for the study of nobiletin metabolism because the order of total amounts of nobiletin metabolites in untreated animals was guinea pigs $>$ hamsters $>$ rats and also guinea pigs formed $4^{\prime}$ $\mathrm{OH}-, 3^{\prime}, 4^{\prime}$-diOH- and 6,7-diOH-metabolites (M-1, M-4 and $\mathrm{M}-5)$ at much higher rates than rats and hamsters. In guinea pig liver, CYP2B18 is known to be one of the important $\mathrm{P} 450$ s because it is constitutive and PB-inducible ${ }^{32-34)}$ and it catalyzes the oxidative metabolism of various substrates such as polychlorinated biphenyls (PCBs), ${ }^{32}$ benzphetamine, ${ }^{33)}$ strychinine $^{33)}$ and tetrahydrocannabinol. ${ }^{34)}$ We observed here that 7-OH- and 6-OH-metabolites (M-2 and M-3) in guinea pigs as well as rats were increased by PB-treatment, suggesting that CYP2B18 is closely associated in the formation of both metabolites. On the other hand, the CYP3A subfamily enzymes are known to be involved in the metabolism of steroids and numerous xenobiotics, ${ }^{17}$ to be highly conserved in mammals, ${ }^{17)}$ and to be induced by various compounds such as dexamethasone, ${ }^{35)}$ macrolide antibiotics ${ }^{36)}$ and $\mathrm{PB} .{ }^{37)}$ The observations in this study that PB accelerated the formation of 7-OH- and 6-OH-metabolites in rats and guinea pigs and of 6-OH-metabolite in hamsters might support the involvement of CYP3A enzymes. By contrast, the time-course study and the immunoinhibition study using antiserum against hamster CYP1A2 indicated that CYP1A1 and CYP1A2 were the most important P450s in the MC-treated animals used in this study.

$4^{\prime}$-Demethylated $\left(4^{\prime}-\mathrm{OH}\right)$-nobiletin has been reported to be the main metabolite in the urine of rats ${ }^{24}$ and mice ${ }^{25)}$ orally administered nobiletin. However, 4'-OH-nobiletin (M1) was not the most abundant metabolite among the five metabolites formed by liver microsomes of untreated rats (Table 1). Although the reason is unclear, 4'-OH-nobiletin might not be metabolized to diOH-metabolites more easily than the other $\mathrm{OH}-$ metabolites in untreated rats. Recently, the biotransformation of nobiletin to $4^{\prime}-\mathrm{OH}-m e t a b o l i t e$ by the fungi Aspergillus niger has been reported. ${ }^{38)}$ This may indicate that the contribution of intestinal microbial flora should be taken into consideration in the in vivo metabolism of nobiletin.

Generally, catechol compounds possessing two adjacent $\mathrm{OH}$-groups in the benzene ring are further oxidized to reactive semiquinone, which may bring about the pharmacological or toxicological activities; for example, catechol-metabo- lites of plant ingredients such as flavonoids show much higher anti-oxidative activities than their parent compounds. ${ }^{39,40)}$ On the other hand, 4- and 2-OH-estradiol-17 $\beta$, the catechol-type metabolites of estradiol-17 $\beta$ are considered to play an important role in estrogen-induced carcinogenesis in hamsters, mice and humans. ${ }^{41-43)}$ As well, catechol metabolites of PCBs, worldwide environmental pollutants, produce oxidative DNA damage via enzymatic and non-enzymatic mechanisms. ${ }^{44)}$ Moreover, an catechol metabolite of 3,4-methylenedioxymethamphetamine, a drug commonly called ecstasy, might be responsible for neurotoxicity including a cognitive dysfunction in humans. ${ }^{45)}$ Minagawa et al. ${ }^{10)}$ has revealed, using various human gastric cancer cell lines such as TMK-1, MKN-45 and St-4, that nobiletin has direct cytotoxicity on TMK-1 cells; whereas it had no significant cytotoxic effect on MKN-45 and St-4 cells. These results might indicate the possibility that the activity in TMK-1 cells to form catechol-metabolites such as M-4 and M-5 is much higher than that in MKN-45 and St-4. Recently, 4'-OH-nobiletin was reported to suppress the SOS response to DNA damage induced by mutagens such as MeIQ, Trp-P-1 and furylfuramide. ${ }^{38)}$ Thus, whether nobiletin or its metabolites exerts the biological effects just described remains unclear. Further studies on the biological effects of the metabolites will be needed to better elucidate the pharmacological significance of nobiletin in animals.

In conclusion, we determined five metabolites of nobiletin formed by liver microsomes of rats, hamsters and guinea pigs and demonstrated that some constitutive P450s such as CYP2C11, CYP2C12, CYP2D1, CYP3A1 and CYP3A2 are responsible for demethylation at the 6-, 7-, 3'- and 4'-positions in rings $\mathrm{A}$ and $\mathrm{B}$, whereas $\mathrm{MC}$-inducible $\mathrm{P} 450 \mathrm{~s}$, CYP1A1 and CYP1A2, preferentially catalyze demethylation at the $3^{\prime}$-and $4^{\prime}$-positions in ring $\mathrm{B}$.

Acknowledgments This work was supported by a grant from the Bio-oriented Technology Research Advancement Institution.

\section{REFERENCES}

1) Kawaii S., Tomono Y., Katase E., Ogawa K., Yano M., J. Agric. Food Chem., 47, 128-135 (1999).

2) Machida K., Osawa K., Chem. Pharm. Bull., 37, 1092-1094 (1989).

3) Chen J., Montanari A. M., Widmir W. W., J. Agric. Food Chem., 45, 364-368 (1997).

4) Mizuno M., Iinuma M., Tanaka T., Matoba Y., Fujii Y., Murata J., Murata H., Iwamasa M., Chem. Pharm. Bull., 35, 3025-3028 (1987).

5) Ishiwa J., Sato T., Mimaki Y., Sashida Y., Yano M., Ito A., J. Rheumatol., 27, 20-25 (2000).

6) Kawaii S., Tomono Y., Katase E., Ogawa K., Yano M., Biosci. Biotechnol. Biochem., 63, 896-899 (1999).

7) Kandaswami C., Perkins E., Soloniuk D. S., Drzewiecki G., Middleton E. Jr., Cancer Lett., 56, 147-152 (1991).

8) Kohno H., Yoshitani S., Tsukio Y., Murakami A., Koshimizu K., Yano M., Tokuda H., Nishino H., Ohigashi H., Tanaka T., Life Sci., 69 901-913 (2001).

9) Kawabata K., Murakami A., Ohigashi H., Biosci. Biotechnol Biochem., 69, 307-314 (2005).

10) Minagawa A., Otani Y., Kubota T., Wada N., Furukawa T., Kumai K., Kameyama K., Okada Y., Fujii M., Yano M., Sato T., Ito A., Kitajima M., Jpn. J. Cancer Res., 92, 1322-1328 (2001).

11) Murakami A., Nakamura Y., Torikai K., Tanaka T., Koshiba T., Koshimizu K., Kuwahara S., Takahashi Y., Ogawa K., Yano M., Tokuda H., Nishino H., Mimaki Y., Sashida Y., Kitanaka S., Ohigashi 
H., Cancer Res., 60, 5059—5066 (2000).

12) Murakami A., Nakamura Y., Ohto Y., Yano M., Koshiba T., Koshimizu K., Tokuda H., Nishino H., Ohigashi H., BioFactors, 12, 187-192 (2000).

13) Lin N., Sato T., Takayama Y., Mimaki Y., Sashida Y., Yano M., Ito A., Biochem. Pharmacol., 65, 2065-2071 (2003).

14) Kawaii S., Tomono Y., Katase E., Ogawa K., Yano M., Anticancer Res., 19, 1261-1269 (1999)

15) Nagase H., Yamakuni T., Matsuzaki K., Maruyama Y., Kasahara J., Hinohara Y., Kondo S., Mimaki Y., Sashida Y., Tank A. W., Fukunaga K., Ohizumi Y., Biochemistry, 44, 13683-13691 (2005).

16) Nagase H., Omae N., Omori A., Nakagawasai O., Tadano T., Yokosuka A., Sashida Y., Mimaki Y., Yamakuni T., Ohizumi Y., Biochem. Biophys. Res. Commun., 337, 1330-1336 (2005).

17) Guengerich F P., Chem.-Biol. Interactions, 106, 161-182 (1997).

18) Nielsen S. E., Breinholt V., Justesen U., Cornett C., Dragsted L. O., Xenobiotica, 28, 389-401 (1998).

19) Nielsen S. E., Breinholt V., Cornett C., Dragsted L. O., Food Chem. Toxicol., 38, 739-746 (2000).

20) Hu M., Krausz K., Chen J., Ge X., Li J., Gelboin H. L., Gonzalez F. J., Drug Metab. Dispos., 31, $924-931$ (2003).

21) Breinholt V. M., Rasmussen S. E., Brosen K., Friedberg T. H., Pharmacol. Toxicol., 93, 14-22 (2003).

22) Murakami A., Kuwahara S., Takahashi Y., Ito C., Furukawa H., Ju-ichi M., Koshimizu K., Biosci. Biotechnol. Biochem., 65, 194-197 (2001).

23) Murakami A., Koshimizu K., Ohigashi H., Kuwahara S., Kuki W., Takahashi Y., Hosotani K., Kawahara S., Matsuoka Y., BioFactors, 16, 73-82 (2002).

24) Yasuda T., Yoshimura Y., Yabuki H., Nakazawa T., Ohsawa K., Mimaki Y., Sashida Y., Chem. Pharm. Bull., 51, 1426-1428 (2003).

25) Li S., Wang Z., Sang S., Huang M.-T., Ho C.-T., Mol. Nutr. Food Res., 50, 291-299 (2006)

26) Yoshihara S., Nagata K., Wada I., Yoshimura H., Kuroki H., Masuda Y., J. Pharmacobio-Dyn., 5, 994-1004 (1982).

27) Koga N., Kikuichi-Nishimura N., Hara T., Harada N., Ishii Y., Yamada H., Oguri K., Yoshimura H., Arch. Biochem. Biophys., 317, 464-470
(1995).

28) Koga N., Kikuichi N., Kanamaru T., Ariyoshi N., Oguri K., Yoshimura H., Biochem. Biophys. Res. Commun., 225, 685-688 (1996).

29) Lowry O. H., Rosebrough N. J., Farr A. L., Randall R. J., J. Biol. Chem., 193, 265-275 (1951).

30) Herz W., Kulanthaivel P., Phytochemistry, 21, 2363-2366 (1982).

31) Watanabe M., Fujii H., Sagami I., Tanno M., Arch. Toxicol., 60, 5258 (1987).

32) Koga N., Kanamaru T., Kikuichi N., Oishi N., Kato S., Yoshimura H., Bull. Environ. Contamin. Toxicol., 60, 898-903 (1998).

33) Oguri K., Kaneko H., Tanimoto Y., Yamada H., Yoshimura H., Arch. Biochem. Biophys., 287, 105-111 (1991).

34) Narimatsu S., Akutsu Y., Matsunaga T., Watanabe K., Yamamoto I., Yoshimura H., Biochem. Biophys. Res. Commun., 172, 607-613 (1990).

35) Schuetz E. G., Wrighton S. A., Barwick J. L., Guzelian P. S., J. Biol. Chem., 259, 1999-2006 (1984).

36) Wrighton S. A., Maurel P., Schuetz E. G., Watkins P. B., Young B., Guzelian P. S., Biochemistry, 24, 2171-2178 (1985).

37) Kim H., Putt D. A., Zangar R. C., Wolf C. R., Guengerich F. P., Edwards R. J., Hollenberg P. F., Novak R. F., Drug Metab. Dispos., 29 , $353-360(2001)$

38) Okuno Y., Miyazawa M., J. Nat. Prod., 67, 1876-1878 (2004).

39) Formica J. V., Regelson W., Food Chem. Toxicol., 33, 1061-1080 (1995).

40) Chen J. W., Zhu Z. Q., Hu T. X., Zhu D. Y., Acta Pharmacol. Sin., 23, $667-672(2002)$.

41) Liehr J. G., Fang W.-F., Sirbasku D. A., Ari-Ulubelen A., J. Steroid Biochem., 24, 353-356 (1986).

42) Newbold R. R., Liehr J. G., Cancer Res., 60, 235-237 (2000).

43) Cavalieri E. L., Rogan E. G., Chakravarti D., Cell Mol. Life Sci., 59, $665-681(2002)$

44) Oakley G. G., Devanaboyina U., Robertson L. W., Gupta R. C., Chem. Res. Toxicol., 9, 1285-1292 (1996).

45) Segura M., Ortuno J., Farre M., McLure J. A., Pujadas M., Pizarro N., Llebaria A., Joglar J., Roset P. N., Segura J., de La Torre R., Chem. Res. Toxicol., 14, 1203-1208 (2001). 